\title{
Formação inovadora em Terapia Ocupacional
}

Patrícia Carla de Souza Della Barba ${ }^{1}$

Roseli Ferreira da Silva ${ }^{2}$

Regina Helena Vitale Torkomian Joaquim ${ }^{3}$

Cristiane Miryam Drumond de Brito ${ }^{4}$

\section{As mudanças na formação em saúde}

Nos últimos anos, a necessidade de mudança na educação de profissionais da saúde tem sido reconhecida amplamente, diante das dificuldades da formação em corresponder às demandas sociais. Dentre os desafios desse processo de mudança, estão a dificuldade em romper com modelos de ensino tradicional e a postura de transmissão de informações para formar profissionais com competências para lidar com as relações humanas no cuidado à saúde (Cyrino, Toralles-Pereira, 2004).

As Instituições de Ensino Superior (IES) enfrentam muitos desafios, dentre eles, o de elaborar, implementar e avaliar boas propostas pedagógicas, traduzidas no desempenho satisfatório do estudante ao longo dos cursos e na formação de qualidade. O acúmulo de conhecimento advindo de diversas áreas, especialmente da educação, traz, nas metodologias alternativas aos modelos tradicionais de ensino, uma perspectiva inovadora que pode atender às demandas do ensino na área de saúde. A partir das experiências iniciadas nas áreas de enfermagem, medicina e odontologia, fomentadas com o objetivo de incentivar as transformações do processo de formação, geração de conhecimentos e prestação de serviços à população para uma abordagem integral do processo de saúdedoença, outros cursos na área da saúde no Brasil iniciam seus movimentos dentro da mesma perspectiva: diminuir o distanciamento entre a academia e o mundo real (dos serviços), alterando, consequentemente, suas metodologias de ensino (Martinez, Della Barba, 2010).

Por outro lado, também as políticas públicas têm ressaltado a necessidade de mudança na formação de profissionais de saúde, apontando para a implementação de currículos integrados e voltados às demandas da população.

De acordo com Ceccim, Armani e Rocha (2002), a Lei Orgânica da Saúde de 1990 aponta, no artigo 15, que os órgãos de gestão do SUS têm como atribuição participar da formação e desenvolvimento de recursos humanos para a saúde, bem como realizar pesquisas e estudos na área da saúde. No artigo 27, destaca, ainda, os serviços de saúde como campos de prática para ensino e pesquisa, colocando, assim, a indissociabilidade das funções de formação e gestão em relação ao contexto de atuação no SUS.

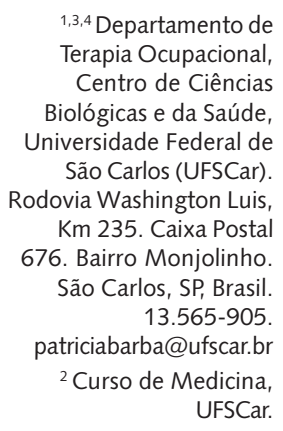

1,3,4 Departamento de Terapia Ocupacional, Centro de Ciências Biológicas e da Saúde, Universidade Federal de São Carlos (UFSCar). Rodovia Washington Luis, Km 235. Caixa Postal 676. Bairro Monjolinho. São Carlos, SP, Brasil. 13.565-905. patriciabarba@ufscar.br

${ }^{2}$ Curso de Medicina, UFSCar. 
Em 1992, logo após a aprovação da Lei Orgânica da Saúde (LOS), a IX Conferência Nacional de Saúde (CNS) indica a necessidade de se assegurarem políticas de capacitação de profissionais da saúde, e reivindica que os gestores garantam escolas de formação de trabalhadores de saúde ou façam a articulação com instituições de nível Superior, sobretudo as universidades públicas (Brasil, 1992).

O texto da X Conferência Nacional de Saúde realizada em 1996 apresenta a deliberação que vem reforçar a necessidade do fortalecimento do vínculo do SUS com as universidades a fim de modificar a formação dos profissionais de saúde, para capacitá-los a atuar na atenção integral à saúde individual e coletiva. Indica, também, a necessidade de revisão dos currículos mínimos dos cursos de graduação em saúde, para que sejam adequados às realidades locais e regionais e às demandas do SUS. O estímulo para a utilização de espaços e serviços do SUS para a formação de trabalhadores de saúde também é ressaltada (Ceccim, Armani, Rocha, 2002).

Ainda, o texto da XI Conferência Nacional de Saúde (CNS) traz a urgência do cumprimento das deliberações da X CNS, que trata da revisão dos currículos dos cursos de nível Superior com a participação dos gestores do SUS e dos conselhos de saúde, além da necessidade de se implementarem novas diretrizes curriculares para os cursos de nível Médio e Superior da área da saúde, de forma a ampliar e incluir disciplinas sobre saúde coletiva (Brasil, 2000).

Nesse sentido, Almeida et al. (2007) afirmam que a aprovação das Diretrizes Curriculares Nacionais (DCN) dos cursos da área da saúde pode ser considerada tanto o resultado de uma mobilização dos educadores da área de saúde no Brasil quanto um reflexo das tendências internacionais, que propõem inovações na formação de profissionais de saúde. Esses autores acrescentam que as DCN trazem a proposta de um perfil profissional com boa formação generalista, humanista, crítico-reflexiva e capaz para desenvolver sua ação por meio de projetos político-pedagógicos construídos de forma coletiva "por atores do curso nas Instituições de Ensino Superior (IES) e que utilizem metodologias de ensinoaprendizagem centradas no estudante em diferentes cenários" (Almeida et al., 2007, p.157).

As Diretrizes Curriculares Nacionais para a área da saúde foram definidas, a partir de 2000, pela Câmara de Educação Superior do Conselho Nacional de Educação, e apontam para a necessidade de currículos integrados que tenham como embasamento um conjunto de áreas de competência articuladas (Conasems, 2008). Indicam, ainda, que o projeto político pedagógico, além de ser construído coletivamente, deve: ser fundamentado na interdisciplinaridade, valorizar as dimensões éticas e humanistas, promover a inserção de docentes e estudantes em serviços existentes nas localidades, fortalecer a parceria ensino-serviço e promover a diversificação de cenários. As DCN também ressaltam que a gestão deve desenvolver um sistema de corresponsabilização, avaliação e acompanhamento, e que a seleção dos conteúdos deve ser orientada às necessidades sociais.

As DCN apontam, como elementos da estrutura curricular, o desenvolvimento de metodologias que ressaltem a participação ativa dos estudantes na construção do conhecimento, sendo que a função principal do educador, nesta abordagem educacional, passa a ser a de mediador/facilitador, capaz de criar situações e condições de aprendizagem a fim de construir saberes a partir dos conhecimentos prévios que os estudantes trazem diante de situações-problema apresentadas, sejam reais ou simuladas (Conasems, 2008). Na mesma direção, a Resolução CNE/CES n06 (Brasil, 2002) institui as Diretrizes Curriculares Nacionais do Curso de Graduação em Terapia Ocupacional.

Em 2008, em consonância com essas e com um processo histórico de transformações do projeto pedagógico em função da realidade da profissão e das demandas da população, o Curso de Graduação em Terapia Ocupacional da Universidade Federal de São Carlos optou por uma mudança curricular pautada nas Metodologias Ativas de Aprendizagem.

Implementar uma prática baseada em um currículo integrado exige a descentralização da lógica disciplinar e um redimensionamento da importância de suas disciplinas para se considerar a importância contextualizada às necessidades da profissão. Assim, o currículo implantado no curso de graduação em Terapia Ocupacional da UFSCar se baseia nas competências que o profissional deve ter ao entrar em contato com sua clientela. Baseia-se em situações reais ou simuladas da prática profissional, garante uma aproximação com o mundo do trabalho, valoriza o potencial das ações observadas e vivenciadas, a fim de formar profissionais terapeutas ocupacionais capazes de planejar e gerir serviços e construir novos modelos de cuidado. 


\section{O currículo por competência}

A noção de competência nos leva ao conceito de excelência que reconhecemos no outro e que define uma área de atuação. Entretanto há distintos modos de se compreender essa excelência e, consequentemente, de desenvolvê-la e verificá-la.

Para o enfrentamento das tensões colocadas, hoje, na formação profissional, faz-se necessário reconhecer a distância entre os problemas do mundo real e a organização disciplinar do conhecimento que orienta a formação profissional tradicional. Desta forma, é necessário incluir uma nova abordagem da relação teoria-prática, com o reconhecimento da natureza complexa e incerta dos problemas existentes no trabalho e, em especial, na área da saúde. Nesse sentido, a interdisciplinaridade e a interlocução de saberes exigida pela abordagem de problemas da prática não podem ser consideradas apenas em sua dimensão de alternativa de diálogo disciplinar, mas no plano da redefinição e construção de novos objetos do conhecimento profissional e de intervenção em saúde (Lima, 2005).

O conceito de competência, que traz novidades para o enfrentamento dos desafios da formação, é defendido por autores como: Perrenoud (1999); Hager e Gonzci (1996) e Hernández (1999). Os autores indicam a competência como "capacidade de mobilizar diferentes recursos [....] para solucionar com pertinência e eficácia uma série de situações" (Lima, 2005, p.373) da prática profissional. Consideramse recursos a aquisição e a aplicação de atributos (cognitivos, psicomotores e afetivos) que, combinados, conformam distintas maneiras de realizar, com sucesso, tarefas essenciais que caracterizam uma determinada prática profissional. Assim, pode-se compreender que diferentes combinações podem resultar nos mesmos padrões de excelência que regem a prática profissional, permitindo que as pessoas desenvolvam um estilo próprio, adequado e eficaz em situações profissionais familiares ou não familiares. Essa abordagem, considerada holística, precisa estar contextualizada no mundo do trabalho, onde as práticas profissionais são desenvolvidas (Lima, 2005).

A competência não é observada diretamente, mas pode se inferir pelo desempenho (realização das tarefas essenciais, fundamentada por atributos qualificados). É importante ressaltar aqui que o conceito de desempenho também não se restringe apenas à realização de uma série de tarefas, definidas de modo tecnificado e avaliadas por uma abordagem descontextualizada em formato de uma lista a ser verificada.

Um enfoque de competência centrado nessa abordagem reduzida de desempenho corre o risco de subestimar o desenvolvimento e a avaliação dos atributos que subjazem e fundamentam as tarefas, e de fragmentar e recortar, de modo extremamente tecnicista, a formação dos profissionais, centrando a aprendizagem no cumprimento de tarefas atomizadas e descontextualizadas.

Por outro lado, um enfoque de competência centrado só nas capacidades ou atributos corre o risco de favorecer o desenvolvimento desarticulado dos domínios cognitivo, psicomotor e afetivo, e de reduzir a prática simplesmente como aplicação da teoria.

Os desempenhos observáveis representam aquilo que o profissional mostra em suas atividades da prática. Os padrões de excelência (critérios de satisfatório) explicitam o que o estudante/profissional deve ser capaz de fazer para desempenhar sua prática com sucesso, mostrando profissionalismo. Também favorecem o desenvolvimento do processo de formação e avaliação profissional, uma vez que os padrões de excelência podem orientar tanto a ação educativa quanto a certificação (UFSCar, 2008).

O diálogo entre mundo do trabalho e da aprendizagem, entre tarefas e capacidades, entre contexto e critérios de excelência, sintetiza as dimensões da competência, observável pelos desempenhos. A abordagem dialógica de competência articula teoria e prática, educação e trabalho, distintas áreas de conhecimento e as dimensões diversas envolvidas num processo de formação.

A noção de competência, em sua função de qualificação social, associa a abordagem cognitivista da competência à dimensão de construção da identidade do sujeito como ator social em sua trajetória de aquisições profissionais. É com base nessa abordagem de competência que pode ser considerada a historicidade dos sujeitos e seu papel de atores de mudanças sociais, contrapondo-se às visões que consideram a aprendizagem como adaptação dos indivíduos a uma ocupação constituída (concepção condutivista). O conceito de competência aqui empregado refere-se às formas e aos meios pelos quais o sujeito contribui, pela apropriação de sua profissão ou ocupação, para reproduzir ou transformar esta mesma ocupação ou profissão (concepção construtivista). 
As áreas de competência definidas para a formação dos terapeutas ocupacionais da UFSCar, que fundamentam e qualificam suas intervenções, são:

1) Cuidado Integral ao Indivíduo - Identificar, no indivíduo, necessidades de âmbito ocupacional; elaborar um plano de intervenção em terapia ocupacional; intervir em terapia ocupacional; avaliar o plano de intervenção; reprogramar metas/ desligamento/encaminhamentos.

2) Cuidado Integral a Grupos - Identificar, no indivíduo, necessidades no âmbito das relações interpessoais que possam ser potencializadas em situação grupal de terapia ocupacional; definir um programa de atividades grupal a partir da identificação de metas compatíveis às demandas de um número de participantes; coordenar grupo de pessoas por meio da realização de atividades em terapia ocupacional; conduzir o grupo de maneira a considerar sua dinâmica nos aspectos das relações interpessoais; coordenar grupos de reflexão sobre temas relativos ao desempenho ocupacional dos participantes; conduzir o olhar para as dinâmicas estabelecidas nas instituições empregando categorias de análise; realizar diagnóstico institucional e reflexão sobre a intervenção do terapeuta ocupacional neste espaço; realizar intervenção em terapia ocupacional levando em consideração a dinâmica institucional e as necessidades de mudanças.

3) Cuidado Integral Coletivo - identificar o estado de saúde da população, isto é, as condições de saúde de grupos populacionais específicos e tendências gerais do ponto de vista epidemiológico, demográfico, socioeconômico e cultural.

4) Investigação em Terapia Ocupacional - participar do processo de trabalho em saúde; investigar sobre a organização social dos serviços e a formulação e implementação de políticas de saúde, bem como avaliar planos, programas e tecnologia utilizada na atenção à saúde; compreender a saúde, incluindo investigações históricas, sociológicas, antropológicas e epistemológicas sobre a produção de conhecimentos neste campo e sobre as relações entre o saber "científico" e as concepções e práticas populares de saúde, influenciadas pelas tradições, crenças e cultura de modo geral. Praticar intervenções em terapia ocupacional, enfatizando: a promoção da saúde, a prevenção de riscos e agravos, a reorientação da assistência a doentes, e a melhoria da qualidade de vida, privilegiando mudanças nos modos de vida e nas relações entre os sujeitos sociais envolvidos no cuidado à saúde.

\section{Currículo integrado}

Neste curso, o currículo é visto como uma práxis, e não como um objeto estático. Currículo como um modelo coerente de pensar a educação ou as aprendizagens necessárias, que não se esgota na parte explícita do projeto escolar. É uma prática da função socializadora e cultural da instituição, que se reagrupa em torno de uma série de subsistemas ou práticas diversas, entre as quais se encontra a prática pedagógica desenvolvida em instituições escolares (Gimeno Sacristán, 1998).

Este enfoque é considerado integrador de conteúdos e formas, o currículo e o ensino estão juntos. Assim, o ensino é visto como o conjunto de atividades que transformam o currículo na prática para produzir aprendizagem. Este currículo que se realiza na prática, segundo Libâneo (1998), supera a dicotomia entre teoria e prática sustentada pelos tecnicistas.

Tal como os princípios propostos por Grundy (apud Gimeno Sacristán, 1998, p.48) são os que norteiam este currículo:

1. uma prática sustentada pela reflexão - práxis, mais do que entender o currículo como um plano que é preciso cumprir, pois se constrói através de uma interação entre a reflexão e a atuação, dentro de um processo circular que compreende o planejamento, a ação e a avaliação, todo integrado em uma espiral de investigação - ação;

2. posto que a práxis tem lugar em um mundo real, e não em um hipotético, o processo de construção do currículo não deve se separar do processo de realização nas condições concretas dentro das quais se desenvolve;

3. a prática opera-se em um mundo de interações, que é o mundo social e cultural, significando com isso que não pode se referir de forma exclusiva a problemas de 
aprendizagem, já que se trata de um ato social, o que leva a contemplar o ambiente de aprendizagem como algo social, entendendo a interação entre o ensino e a aprendizagem dentro de determinadas condições;

4. o mundo da práxis é um mundo construído, não natural, assim o conteúdo do currículo é uma construção social. Através da aprendizagem, os estudantes se tornam participantes ativos da elaboração de seu próprio saber, o que deve obrigá-los à reflexão sobre o conhecimento, incluindo o professor;

5. do princípio anterior se deduz que a práxis assume o processo de criação de significado como construção social, com conflitos, pois se descobre que esse significado acaba sendo imposto pelo que tem mais poder para controlar o currículo.

Desta forma, no currículo do curso de Terapia Ocupacional, todas as Unidades Educacionais são planejadas em conjunto, ou seja, os docentes de diferentes áreas se reúnem ao longo do ano para a construção do programa e das atividades - agregam-se a estes, também, os profissionais da Rede Escola de Cuidados de Saúde, em especial nas Unidades de Prática.

É importante reconhecer o caráter social da escola nesta concepção do currículo como configurador da prática. O objetivo básico nesta visão da socialização dos estudantes é prepará-los para sua incorporação ao mundo do trabalho. Isto significa desenvolver, nas novas gerações de estudantes, não só conhecimentos, ideias, habilidades e capacidades formais, mas, também, desenvolver disposições, atitudes, interesses e padrões de comportamento. Um segundo objetivo do processo de socialização da escola é a formação do cidadão para a sua intervenção na vida pública (Gimeno Sacristán, Pérez Gómez, 1998).

O currículo integrado do curso de graduação em Terapia Ocupacional está organizado, em cada série, por unidades educacionais interdisciplinares, e são estruturadas a partir dos desempenhos que são desenhados para cada uma das áreas de competência, esperados para os estudantes em cada série. Estas unidades são: Unidade Educacional de Referenciais Teóricos e Metodológicos em Terapia Ocupacional - URTMTO; Unidade Educacional de Recursos e Atividades em Terapia Ocupacional UREATO; Unidade Educacional de Prática Supervisionada em Terapia Ocupacional - UPSTO; Unidade Educacional de Pesquisa em Terapia Ocupacional - UPTO, e Unidade Educacional de Atividades Complementares - UAC.

Na Unidade Educacional de Referenciais Teóricos e Metodológicos em Terapia Ocupacional são utilizadas situações simuladas da prática e investigativas; o estudante é incentivado a construir, ativamente, criativamente, reflexivamente e de forma autônoma, o seu conhecimento a partir de disparadores como: situações de papel, filmes, textos, reportagens, fotos, entre outros. Tal como na aprendizagem baseada em problemas, o conhecimento é construído num processo espiral, que ocorre num primeiro momento de síntese provisória: reconhecimento dos conhecimentos prévios do estudante, o levantamento de hipóteses e formulação de questões de aprendizagem; em seguida, um momento individual de busca e estudos; e um terceiro momento de nova síntese, no qual os estudantes compartilham os conhecimentos construídos individualmente e passam a elaborar uma nova síntese sobre as questões de aprendizagem elaboradas anteriormente.

Todo esse processo é acompanhado por uma avaliação formativa da aprendizagem do estudante, que objetiva identificar: a exploração do conhecimento prévio dos mesmos, o desenvolvimento do raciocínio clínico e epidemiológico, a formulação de hipóteses, a busca e análise crítica do conhecimento necessário para melhor explicar o problema, e a formulação de planos de cuidado para situações individuais e coletivas. O professor, nesta atividade, exerce a função de facilitador do grupo de aprendizagem.

Na Unidade Educacional de Recursos e Atividades em Terapia Ocupacional, o objetivo principal é proporcionar, ao estudante, a experiência para explorar recursos pessoais, técnicos e de atividades, para habilitá-lo na condução de processos terapêuticos e outras ações de intervenção em terapia ocupacional. Objetiva, ainda, possibilitar que o aluno identifique, entenda, analise e interprete o fazer humano e as suas desordens. Pretende-se que o estudante adquira capacidades para analisar e utilizar, como instrumentos de intervenção, as diferentes atividades humanas, quais sejam: as artes, o trabalho, 
o lazer, a cultura, as atividades artesanais, o autocuidado, as atividades cotidianas e sociais. Assim, nessa unidade, o estudante se aproxima gradativamente de materiais e técnicas, a princípio, identificando o que e como "o fazer" dessas atividades e vivências repercute em si mesmo, para, depois, a partir do procedimento de Análise de Atividade, ser capaz de oferecer uma atividade significativa e contextualizada ao usuário sob sua ação.

$\mathrm{Na}$ Unidade Educacional de Prática Supervisionada em Terapia Ocupacional, o estudante é inserido no contexto real do trabalho nos diferentes campos de ação do terapeuta ocupacional, nos quais, para as atividades de prática supervisionada, o curso conta com a participação de preceptores dos serviços onde os estudantes estão inseridos, portanto, constituindo um trabalho de parceria universidade-serviço. Em pequenos grupos, tendo o professor como facilitador, num momento de reflexão da prática, os disparadores emergem da problematização contextual, o estudante constrói o conhecimento individualmente e coletivamente, seguindo os mesmos momentos em espiral - síntese provisória, busca e nova síntese. O objetivo é qualificar o estudante a realizar aprendizagens significativas em ampla gama de situações e circunstâncias (Coll, 2000) advindas da experiência com as diversas práticas da terapia ocupacional, por meio do acompanhamento e participação em atendimentos e ações supervisionadas pelo preceptor, junto a indivíduos e grupos-alvo da terapia ocupacional, desde as séries iniciais do curso, nas diferentes áreas, instituições e níveis de atuação, em atividades de complexidade crescente que envolve a observação, a prática assistida e a prática autônoma supervisionada.

A Unidade Educacional de Pesquisa em Terapia Ocupacional objetiva oferecer, ao aluno: os conhecimentos básicos de técnicas e métodos para a iniciação científica, os conhecimentos sobre os pressupostos e procedimentos do estudo da terapia ocupacional, desenvolvendo sua reflexão e sua capacidade crítica de modo a instrumentalizá-lo para propor e executar investigação.

A Unidade Educacional de Atividades Complementares compreende todas as atividades de caráter acadêmico-científico, cultural, artístico, esportivo, político e social, desenvolvidas durante o Curso de Terapia Ocupacional da UFSCar, que não estão compreendidas no desenvolvimento regular das atividades do Curso.

O Quadro 1 sintetiza as unidades educacionais previstas para os cinco anos do curso e indica como as mesmas estão distribuídas ao longo dos anos.

Quadro 1. Estrutura curricular do Curso de Terapia Ocupacional da UFSCar

\begin{tabular}{|l|l|}
\hline Ano & \multicolumn{1}{c|}{ Unidades educacionais } \\
\hline $1^{\circ}$ Ano & $\begin{array}{l}\text { Referenciais Teóricos e Metodológicos em Terapia Ocupacional I } \\
\text { Prática Supervisionada em Terapia Ocupacional I } \\
\text { Recursos e Atividades em Terapia Ocupacional I } \\
\text { Pesquisa em Terapia Ocupacional I }\end{array}$ \\
\hline $2^{\circ}$ Ano & $\begin{array}{l}\text { Referenciais Teóricos e Metodológicos em Terapia Ocupacional II } \\
\text { Prática Supervisionada em Terapia Ocupacional II } \\
\text { Recursos e Atividades em Terapia Ocupacional II } \\
\text { Pesquisa em Terapia Ocupacional II }\end{array}$ \\
\hline $3^{\circ}$ Ano & $\begin{array}{l}\text { Referenciais Teóricos e Metodológicos em Terapia Ocupacional III } \\
\text { Prática Supervisionada em Terapia Ocupacional III } \\
\text { Recursos e Atividades em Terapia Ocupacional III } \\
\text { Pesquisa em Terapia Ocupacional III }\end{array}$ \\
\hline $4^{\circ}$ Ano & $\begin{array}{l}\text { Referenciais Teóricos e Metodológicos em Terapia Ocupacional IV } \\
\text { Prática Supervisionada em Terapia Ocupacional IV } \\
\text { Recursos e Atividades em Terapia Ocupacional IV } \\
\text { Pesquisa em Terapia Ocupacional IV }\end{array}$ \\
\hline $5^{\circ}$ Ano & $\begin{array}{l}\text { Referenciais Teóricos e Metodológicos em Terapia Ocupacional V } \\
\text { Prática Supervisionada em Terapia Ocupacional V } \\
\text { Pesquisa em Terapia Ocupacional V }\end{array}$ \\
\hline
\end{tabular}




\section{Concepção pedagógica}

Tem sido um desafio elaborar propostas pedagógicas que dialoguem com a revolução tecnológica da informação e da comunicação deste século, em que o conhecimento está disponível em rede globalizada. Agora, é possível processar, armazenar, recuperar e comunicar informação em qualquer formato, sem interferência de fatores como distância, tempo ou volume. O global e o local se liquefazem em uma nova realidade, no entanto não é garantido que o conhecimento crie sentidos para o sujeito ou interaja numa rede complexa de comunicação. Para se pensar em educação no século atual, é necessário refletir sobre esses processos. O conhecimento não está mais restrito a um momento da vida nem ao espaço da escola ou a um conjunto predeterminado de saberes. $\mathrm{Na}$ sociedade do conhecimento, a regra é ser capaz de aprender ao longo da vida (Brito, 2008). É visível a profusão da informação e a livre circulação de dados, no entanto, isso não garante o conhecimento e a construção de uma formação reflexiva.

Assim, como fazer com que os profissionais a serem formados na universidade possam construir o conhecimento de maneira autônoma, significativa, complexa, aprofundada e contínua? A ideia tem sido abandonar concepções tradicionais de ensino-aprendizagem e adotar concepções crítico-reflexivas, nas quais o estudante é construtor de seu conhecimento, indagando sua própria prática. A proposta é formar um profissional reflexivo, capaz de "interagir com o conhecimento de forma autônoma, flexível e criativa; é a melhor preparação para a vivência no nosso mundo super complexo, incerto, sempre pronto a exigir novos saberes, inspiradores de novas ações" (Alarcão, 2003, p.30).

Desta forma o desafio é construir um projeto pedagógico capaz de gerar reflexões e transformações: nos serviços de saúde, nos serviços de assistência social, na universidade, no professor, no profissional de saúde, no aluno e no próprio currículo, em um processo de avaliação contínua.

Assim, o objetivo do projeto pedagógico também é buscar a autonomia e cidadania do estudante e gerar capacidade crítica-reflexiva no mesmo através da inserção no contexto real do trabalho, transformando e fortalecendo - no caso dos profissionais de saúde - o SUS.

O processo de ensino-aprendizagem e a própria construção do projeto pedagógico devem ser ativos. Todos os atores envolvidos problematizam seus saberes e práticas. O estudante inserido no processo de trabalho, a partir de sua visão de mundo, problematiza e realiza buscas, reproblematiza seus conhecimentos, do grupo e do local de trabalho no qual está inserido. A ideia é proporcionar, aos participantes do processo, uma aprendizagem cooperativa, um aprender de forma significativa, o que pressupõe pensar, investigar, conhecer, crescer com competência e habilidade (Brito, 2008).

Portanto, o conhecimento é social e deve ser desenvolvido em rede social, pressupõe a cultura e a vida social como determinante na maneira de pensar das pessoas. As pessoas se desenvolvem ao longo do tempo, mediadas pelo social por meio dos símbolos criados pela cultura. Os conceitos são construídos e internalizados de maneira não linear e diferente para cada pessoa. O cotidiano está sempre em movimento, em transformação. Essas ideias auxiliam na construção do projeto pedagógico, que não é algo estático, assim, é capaz de se transformar ao ser colocado em prática ao longo do tempo. A consideração do universo cultural, da apreensão do saber mediado pelo social e pela cultura, trouxe a ideia do construtivismo, e, então, de uma concepção de aprendizagem socioconstrutivista (Vygotsky, 1999).

O socioconstrutivismo tem como foco de aprendizagem as interações sociais mediadas por um facilitador. Os atores envolvidos entram em contato entre si através de conhecimentos prévios, com novas descobertas e, assim, organizam o conhecimento juntos. O trabalho em grupo é uma ferramentachave para a busca do conhecimento, mas conserva-se, no projeto, a autonomia da busca individual, os conhecimentos acumulados pela história de vida de cada um, e tudo isso compartilhado com o grupo, gerando novos significados. A aprendizagem significativa requer "Uma intensa atividade do estudante, que deve estabelecer relações entre o novo conteúdo e os elementos já disponíveis em sua estrutura cognoscitiva; julgar e decidir a maior pertinência dos mesmos, ampliá-los ou diferenciá-los em função das novas informações" (Coll, 2000, p.23).

Todo o processo de ensino-aprendizagem no curso de Terapia Ocupacional da UFSCar é vivenciado de forma ativa. Os conhecimentos prévios do estudante são sempre considerados, seja em unidades 
realizadas em pequenos grupos e/ou em unidades que simulam práticas laboratoriais, na análise do campo científico da Terapia Ocupacional e/ou na imersão em processos reais de trabalho. O currículo exige uma postura ativa, crítica e reflexiva do estudante, no qual a capacidade de relações do conhecimento e saber que o mesmo realiza pode ser infinitas. O professor tem a responsabilidade de ajudar o estudante a desenvolver, de maneira gradativa, a capacidade de transformar a informação em conhecimento, que, quando refletido à luz dos valores universais, pode revestir a forma do agir sábio (Silva, Sá-Chaves, 2008).

As unidades educacionais têm diferenças na forma organizativa, mas têm em comum o processo de construção do conhecimento e a relação do professor-estudante neste processo. Assim, compreende-se que o processo de ensino- aprendizagem é vivenciado contextualmente, incluindo problemáticas, angústias e diálogos. Valoriza-se o conhecimento cotidiano e o mundo real do trabalho, transformando-o. A dialógica de Freire e Morin são princípios fundamentais nesta proposta pedagógica (Morin, 2001; Freire, 1983).

O estudante do curso de graduação em Terapia Ocupacional da UFSCar insere-se na atenção básica em saúde no primeiro e segundo ano, e constrói conceitos de forma interdisciplinar, com reflexões em pequenos grupos. No terceiro ano, dialoga com a atenção especializada em diversas áreas de atuação da Terapia Ocupacional, em uma mesma postura dialógica e ativa, continuando, no quarto e quinto anos, em cenários diversificados de atenção primária, secundária e terciária, em estágios supervisionados, de forma mais autônoma.

Há momentos diferenciados no processo de ensino-aprendizagem, momentos em que o estudante vivencia situações reais da prática profissional e essa vivência gera conflitos, diálogos, interações que servem como disparadores de aprendizagem, proporcionando reflexões, conscientização profissional e de cidadão, inter-relacionando habilidades e dimensões humanas necessárias para a formação profissional: a afetiva, a cognitiva, a sociocultural e a psicomotora.

Há outros momentos de aprendizagem em que a realização de reflexões e a construção do conhecimento se dão a partir de situações de papel, que representam a prática profissional do terapeuta ocupacional em seus diferentes campos, os quais são utilizados como disparadores. E, ainda em outros momentos, se tem a simulação da prática terapêutica ocupacional, com inserção de recursos terapêuticos possíveis de serem utilizados na prática profissional. E, ainda, há espaços para a pesquisa em terapia ocupacional nos quais o estudante irá construir e efetivar, a partir de suas inquietações e da literatura cientifica em terapia ocupacional, seu projeto de pesquisa.

Em todos esses espaços se realizam, cotidianamente, avaliações formativas, nas quais todos os atores envolvidos se autoavaliam e avaliam seus pares, os professores assumindo o papel de facilitadores e preceptores. A comunicação estabelecida entre os diversos sujeitos, estudantes, profissionais da equipe de saúde, pacientes e professores, mostra-se relevante para o desenvolvimento da aprendizagem. Entende-se que a avaliação se constitui em um espaço de aprendizagem, o qual permite, aos sujeitos envolvidos, a tomada de consciência da situação de aprendizagem, levando-os à reorientação do processo de construção do conhecimento. Desta forma, valoriza-se, em todos os espaços, a reflexão, no processo de formação profissional do terapeuta ocupacional. Segundo Schön (2000), a aquisição do conhecimento profissional enquanto um processo, no qual um resultado inesperado pode levar à reflexão (reflexão-na-ação), que tem uma função crítica, questionando a estrutura de pressupostos do ato de conhecer-na-ação.

O projeto pedagógico do curso de terapia ocupacional da UFSCar se insere em um dos desafios deste século, que é o de formar pessoas capazes de se desenvolverem de forma autônoma, crítica e reflexiva; ser um agente transformador de si mesmo e da sociedade, dialogando com os quatro pilares fundamentais propostos pela Unesco: o aprender a conhecer, aprender a fazer, aprender a conviver e aprender a ser (Delors, 1996). 


\section{Metodologias ativas de aprendizagem}

Segundo Mitre et al. (2008) as vertiginosas transformações das sociedades contemporâneas têm colocado em questão os aspectos relativos à formação profissional, sobretudo na saúde, na medida em que a indissociabilidade entre teoria e prática, o desenvolvimento de uma visão integral do homem e a ampliação da concepção de cuidado tornam-se prementes para o adequado desempenho no trabalho. Para os autores, o grande desafio está na perspectiva de se desenvolver a autonomia individual em íntima coalizão com o coletivo. Cabe à educação ser capaz de desencadear uma visão de interdependência e de transdisciplinaridade, além de possibilitar a construção de redes de mudanças sociais. Para tal, verifica-se crescente tendência à busca de métodos inovadores, que admitam uma prática pedagógica ética, crítica, reflexiva e transformadora, ultrapassando os limites do treinamento puramente técnico, para efetivamente alcançar a formação do homem como um ser histórico, inscrito na dialética da ação-reflexão-ação.

A habilidade de problematizar, como a habilidade de relacionar de forma coerente e sequencial, possui três momentos: identificação de um problema; busca de explicação, e proposição de soluções, sendo essa habilidade alvo da ação educativa (Zanotto, De Rose, 2003). Segundo as autoras, o ensino dessa habilidade pode ser planejado por meio de qualquer metodologia que se refere ao estudo de problemas, mas o que é comum a todas elas é que estão pautadas no trinômio PROBLEMA EXPLICAÇÃO - SOLUÇÃO. Dessa forma, o aluno deve relacionar três momentos ou movimentos: identificação de um problema, busca de fatores explicativos e proposição de solução ou soluções.

Assim, problematizar seria mais do que formular questões ou perguntas, como se encontra no léxico, porque nem toda pergunta contém um problema. Problematizar significa ser capaz de responder ao conflito que o problema traz de forma intrínseca e que o sustenta (Zanotto, De Rose, 2003). Propostas que enfatizam esse tipo de ação podem ser denominadas de metodologias que enfatizam a ação de problematizar, porque todas têm como objetivo último que o aluno aprenda a relacionar estes três momentos: identificação de um problema, busca de fatores explicativos e proposição de solução ou soluções.

O currículo do curso de Terapia Ocupacional da UFSCar utiliza as metodologias ativas, tal como: Aprendizagem Baseada em Problemas, seguindo esquema da espiral construtivista nas Unidades Educacionais de Referenciais Teóricos e Metodológicos em Terapia Ocupacional, descrita na Figura 1 (UFSCar, 2008); e Aprendizagem Baseada na Prática (problematização), nas Unidades Educacionais de Prática Supervisionada em Terapia Ocupacional, representada pelo esquema do arco segundo Charles Maguerez, descrita na Figura 2 (Diaz Bordenave, Pereira, 1991). A escolha destas duas metodologias para estas unidades educacionais se relaciona com o enfoque de cada uma, pois a primeira está mais associada a questões teóricas e investigativas, e a outra trabalha a prática da terapia ocupacional no contexto real do trabalho.

A esquematização do processo de ensino-aprendizagem na forma de uma espiral busca representar os movimentos desenvolvidos no trabalho coletivo dos grupos de aprendizagem nas Unidades Educacionais de Referenciais Teóricos e Metodológicos (Figura 1).

A esquematização do processo de ensino-aprendizagem na forma de arco busca representar os movimentos desenvolvidos no processo de ação-reflexão-ação desenvolvidos nas Unidades Educacionais de Prática Supervisionada (Figura 2).

Dessa forma, a aprendizagem se torna significativa, e, quando isso ocorre, ela permite não somente a formação profissional do aluno, mas seu crescimento pessoal, construindo conceitos, processos e valores. 
Figura 1. Espiral construtivista do processo de ensino-aprendizagem a partir da exploração de uma situação-problema (Lima, 2002)

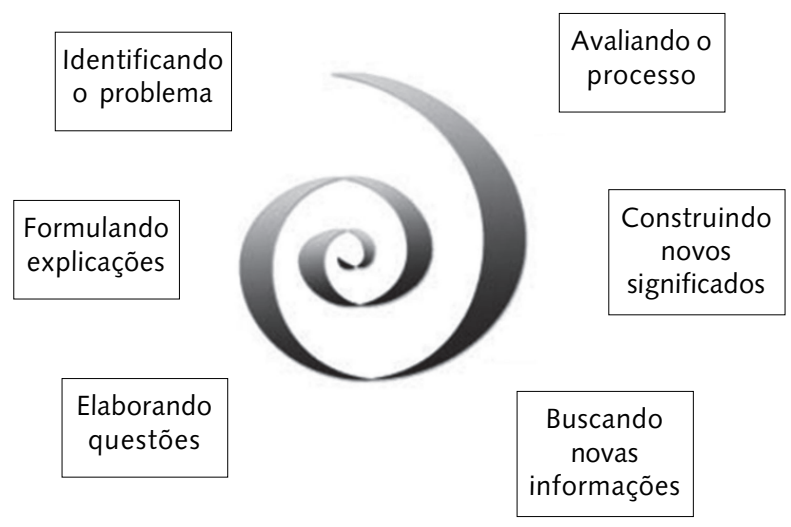

Figura 2. Esquema do Arco, segundo Charles Maguerez (Diaz Bordenave; Pereira, 1991)

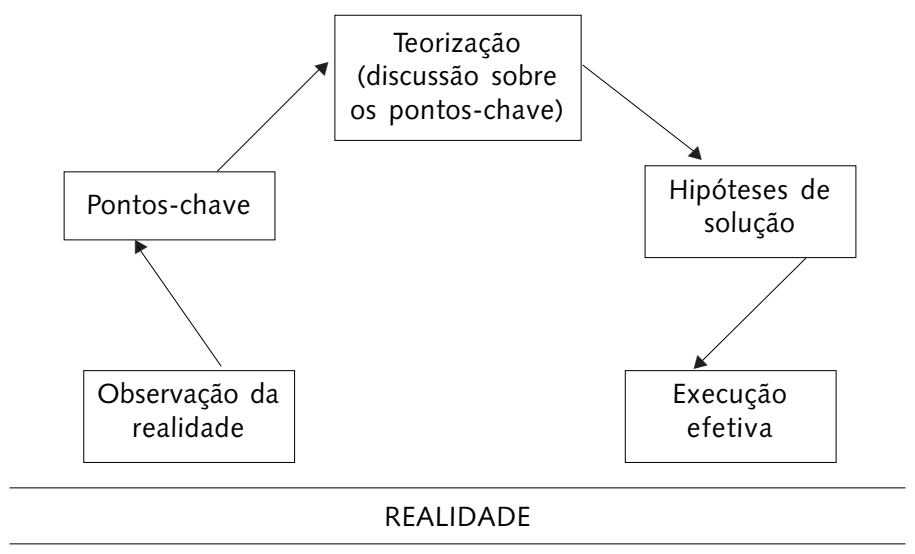

\section{Considerações finais}

Ao longo de quatro anos de implantação do novo currículo no curso de graduação em Terapia Ocupacional da UFSCar, tem sido possível identificar alguns resultados.

Dentre eles, pode-se destacar que a metodologia adotada tem possibilitado, aos estudantes, a aprendizagem significativa, o que permite não somente a formação profissional do aluno, mas seu crescimento pessoal, a construção de conceitos, processos e valores.

Além disso, quando as situações-problema são disparadas de forma articulada com a vivência do estudante nos cenários de prática, tem sido constatado o estímulo do estudante em participar ativamente na busca de referenciais teóricos qualificados, debatê-los e sistematizar possibilidades de ação. 
A parceria com a Rede Escola de Cuidados à Saúde do município tem possibilitado a aproximação com o contexto real da prática da terapia ocupacional e de equipes de saúde, bem como tem potencializado as trocas de informações e práticas. O envolvimento direto dos estudantes com preceptores terapeutas ocupacionais tem sido avaliado como positivo, com ganhos para ambosestudantes e preceptores; os primeiros porque desenvolvem competência para lidar com situações da prática profissional nos cenários reais, tendo como modelo os terapeutas ocupacionais; e estes, por sua vez, são comprometidos com o processo de ensino-aprendizagem e estão em contato direto com capacitações em serviço, participação em congressos, projetos e publicações em conjunto com os docentes da universidade.

Nesse período de quatro anos, tem sido constatado um convívio compartilhado entre facilitadordocente, preceptor-profissional da terapia ocupacional, equipe multidisciplinar, usuários e estudante, o que resulta em uma formação crítico-reflexiva do terapeuta ocupacional.

Os estudantes têm se responsabilizado pelo acompanhamento de indivíduos e famílias em variados momentos do ciclo de vida (famílias com gestantes e crianças pequenas, famílias com adolescentes, famílias com adultos e idosos), tanto na atenção básica como especializada, compreendendo saúde de forma ampliada e realizando ações em crescente nível de complexidade e de acordo com as especificidades da terapia ocupacional.

Os estudantes têm sido orientados a basearem suas atitudes e reflexões em diálogo com a produção científica, tanto na área de saúde coletiva quanto na área específica da terapia ocupacional.

Por outro lado, alguns desafios têm sido encontrados no processo de implantação deste novo currículo. As questões estruturais da universidade, muitas vezes, dificultam o avanço em etapas consideradas importantes. Como exemplos: o sistema operacional de registro de notas e avaliações da universidade não tem acompanhado a necessidade de avaliação processual do estudante, das unidades educacionais e dos facilitadores, que é baseada em desempenhos a serem desenvolvidos, questão essa fundamental no projeto pedagógico; a sustentação de um programa de educação permanente para todo o corpo docente e preceptores, fundamental para o processo de se tornar um docente-facilitador, tem dificuldades para se manter na rotina dos professores e, consequentemente, da universidade.

O enfrentamento constante do receio sobre a efetividade de um currículo não mais baseado em disciplinas básicas e específicas, mas sim em unidades educacionais integradas - que se complementam e têm um crescente grau de complexidade - também pode ser citado como um desafio a ser enfrentado no modelo proposto.

Assim, são muitas as expectativas em relação aos professores, preceptores e estudantes de terapia ocupacional. Com a implantação do projeto pedagógico, espera-se que o egresso seja coeso com a prática profissional da terapia ocupacional, compromissado com sua aprendizagem desde o início do curso e capaz de se tornar um agente de transformação na sociedade, a partir de suas vivências reais na universidade e comunidade em seu entorno. Espera-se, também, que os docentes e preceptores estejam dispostos a rever seus modelos de ensino-aprendizagem, colocando-se disponíveis para a construção coletiva desse processo, que acredita-se oferecer ganhos para todos os envolvidos.

\section{Colaboradores}

Patrícia Carla de Souza Della Barba e Roseli Ferreira da Silva participaram de todas as etapas da construção do manuscrito, desde a concepção e desenho, análise, redação e revisão final. Regina Helena Vitale Torkomian Joaquim e Cristiane Miryam Drumond de Brito participaram da análise e redação do trabalho. 


\section{Referências}

ALARCÃO, I. Professores reflexivos em uma escola reflexiva. São Paulo: Cortez, 2003.

ALMEIDA, M.J. et al. Implantação das Diretrizes Curriculares Nacionais na Graduação em Medicina no Paraná. Rev. Bras. Educ. Med., v.31, n.2, p.156-65, 2007.

BRASIL. Ministério da Educação. Resolução CNE/CES n.6, de 19 de fevereiro de 2002. Diretrizes Curriculares Nacionais do curso de graduação em Terapia Ocupacional. Brasília, 2002. Disponível em: <http://portal.mec.gov.br/cne/arquivos/pdf/ CES062002.pdf >. Acesso em: 23 jan. 2011.

$1^{\text {a }}$ Conferência Nacional de Saúde: Efetivando o SUS: acesso, qualidade e humanização na atenção à saúde, com controle social: Relatório final. Brasília: Ministério da Saúde, 2000.

$1^{\text {a }}$ Conferência Nacional de Saúde: Saúde: municipalização é o caminho: Relatório final. Brasília: Ministério da Saúde, 1992.

BRITO, C.M.D. Formação do Terapeuta Ocupacional no século XXI. Rev. Baiana Saude Publ., v.32, supl.1, p.29-39, 2008.

CECCIM, R.B.; ARMANI, T.B.; ROCHA, C.F. O que dizem a legislação e o controle social em saúde sobre a formação de recursos humanos e o papel dos gestores públicos, no Brasil. Cienc. Saude Colet., v.7, n.2, p.373-83, 2002.

COLL, C. Psicologia e currículo: uma aproximação psicopedagógica a elaboração do currículo escolar. São Paulo: Ática, 2000.

CONASEMS. A formação de profissionais de saúde em sintonia com o SUS: currículo integrado e disciplinar. Brasília: Núcleo de Gestão do Trabalho e Educação na Saúde do CONASEMS, 2008.

CYRINO, E.G.; TORALLES-PEREIRA, M.L. Trabalhando com estratégias de ensinoaprendizado por descoberta na área da saúde: a problematização e a aprendizagem baseada em problemas. Cad. Saude Publica, v.20, n.3, p.780-8, 2004.

DELLA BARBA, P.C.S. Vivência em cenários reais na formação do estudante de Terapia Ocupacional: algumas reflexões do facilitador. In: CONGRESSO INTERNACIONAL PBL 2010 - APRENDIZAGEM BASEADA EM PROBLEMAS E METODOLOGIAS ATIVAS DE APRENDIZAGEM, 2010, São Paulo. Anais... São Paulo, 2010. v.R0231. p.1-10.

DELORS, J. (Coord.). Educação, um tesouro a descobrir. Relatório para a Unesco da Comissão Internacional sobre Educação para o século XXI. Porto: ASA, 1996.

DIAZ BORDENAVE, J.; PEREIRA, A.M. Estratégias de ensino-aprendizagem. 12.ed. Petrópolis: Vozes, 1991.

FREIRE, P. Educação como prática da liberdade. Rio de Janeiro: Paz e Terra,1983.

GIMENO SACRISTÁN, J. O currículo: uma reflexão sobre a prática. 3.ed. Porto Alegre: Artes Médicas, 1998.

GIMENO SACRISTÁN, J.; PÉREZ GÓMEZ, A.I. Compreender e transformar o ensino. 4.ed. Porto Alegre: Artes Médicas, 1998.

HAGER, P.; GONCZI, A. What is competence? Med. Teach., v.18, n.1, p.15-8, 1996. HERNÁNDEZ, D. La certificación por competências: um desafio. In: ANALES DEL 1999. Anales... Reunión de dirigentes de instituciones de Educación tecnológica, Aracaju: CEFET, 1999.

LIBANEO, J.C. Os campos contemporâneos da didática e do currículo: aproximações e diferenças. In: OLIVEIRA, M.R.N.S. (Org.). Confluências e divergências entre didática e currículo. Campinas: Papirus, 1998. p.53-92. 
LIMA, V.V. Competência: distintas abordagens e implicações na formação de

profissionais de saúde. Interface - Comunic., Saude, Educ., v.9, n.17, p.369-79, 2005.

Learning issues raised by students during PBL tutorials compared to curriculum objectives. 2002. Dissertação (Mestrado) - Department of Health Education, University of Illinois at Chicago, Chicago. 2002.

MARTINEZ, C.M.S.; DELLA BARBA, P.C.S. Motivação de alunos de graduação em Terapia Ocupacional no processo de aprender a aprender. In: CONGRESSO INTERNACIONAL PBL 2010 - APRENDIZAGEM BASEADA EM PROBLEMAS E METODOlOGIAS ATIVAS DE APRENDIZAGEM, 2010, São Paulo. Anais... São Paulo, 2010. v.R0231, p.1-8.

MITRE, S.M. et al. Metodologias ativas de ensino-aprendizagem na formação profissional em saúde: debates atuais. Cienc. Saude Colet., v.13, supl.2., p.2133-44, 2008.

MORIN, E. A religação dos saberes: o desafio do século XXI. Rio de Janeiro: Bertrand Brasil, 2001.

PERRENOUD, P. Construir competências desde a escola. Porto Alegre: Artes Médicas Sul, 1999.

SCHÖN, D. Educando o profissional reflexivo: um novo design para o ensino e a aprendizagem. Porto Alegre: Artes Médicas, 2000. SILVA, R.F.; SÁ-CHAVES, I. Formação reflexiva: representações dos professores acerca do uso de portfólio reflexivo na formação de médicos e enfermeiros. Interface - Comunic., Saude, Educ., v.12, n.27, p.721-34, 2008.

UFSCAR - UNIVERSIDADE FEDERAL DE SÃO CARLOS. Coordenação do Curso de Medicina. Caderno do curso de medicina. São Carlos: UFSCAR, 2008.

VYGOTSKY, L.S. A formação social da mente. São Paulo: Martins Fontes, 1999.

ZANOTTO, M.A.C.; DE ROSE, T.M.S. Problematizar a própria realidade: análise de uma experiência de formação contínua. Educ. Pesqu., v.29, n.1, p.45-54, 2003. 
As instituições de Ensino Superior enfrentam o desafio de implementarem propostas pedagógicas traduzidas no desempenho satisfatório do estudante para uma formação de qualidade. Ainda, as políticas públicas ressaltam a necessidade de mudança na formação de profissionais de saúde voltada para as necessidades da população.

Descreve-se a construção do projeto pedagógico do curso de Terapia Ocupacional (TO) da Universidade Federal de São Carlos, no qual se propõe a formação reflexiva, levando o formando a interagir com o conhecimento de forma autônoma, flexível e criativa. O currículo é integrado, interdisciplinar e orientado por competência, no qual a prática profissional é fundamentada em capacidades voltadas para o enfrentamento de situações em diferentes contextos. A concepção pedagógica adotada é a socioconstrutivista, e são utilizadas metodologias ativas de ensino-aprendizagem, tais como a aprendizagem baseada em problemas e problematização.

Palavras-chave: Terapia ocupacional. Currículo. Competências. Metodologias de ensino-aprendizagem.

\section{Innovative training in Occupational Therapy}

Higher education institutions face the challenge of implementing educational proposals that lead the students to satisfactory development for quality training. Moreover, public policies highlight the need for changes in healthcare professionals' training regarding the population's needs. This article describes the creation of the pedagogical project for the occupational therapy course at the Federal University of São Carlos. Reflective education was proposed, thereby leading students to interact with knowledge in an independent, flexible and creative way. This is an integrated, interdisciplinary and competence-oriented curriculum. Its professional practice is based on abilities focused on dealing with situations in different contexts. The pedagogical conceptualization was based on the socioconstructivism theory. Active teaching and learning methodologies such as problem-based learning and problem-setting are used.

Keywords: Occupational Therapy. Curriculum. Competences. Teaching-learning methodology.

\section{Formación innovadora en Terapia Ocupacional}

Las instituciones de enseñanza superior afrontan el desafío de implementar propuestas que se traducen en un desempeño satisfactorio del estudiante para una formación de calidad. Las políticas públicas destacan la necesidad de cambio en la formación de los profesionales de la salud de acuerdo con las necesidades de la población. Se describe el proyecto pedagógico del curso de Terapia Ocupacional (TO) de la Universidade Federal de São Carlos, Brasil, en el cual se propone la formación reflexiva, que hace con que el alumno interactúe con el conocimiento de una manera autónoma, flexible y creativa. Es un currículo integrado, interdisciplinario y orientado por competências. La práctica profesional se basa en afrontar situaciones en contextos diferentes. Está adaptada en el socio-constructivismo y se utiliza de metodologías activas como el aprendizaje basado en problemas y la problematismo.

Palabras clave: Terapia Ocupacional. Currículo. Competencias. Metodologías de enseñanza y aprendizaje.

Recebido em 03/09/11. Aprovado em 25/01/12 